\title{
The Effects of COVID-19 on Mental Health, Socio-Economic Issues, and Social Interactions in Tehran: A Pilot Study
}

\section{Pir Hossein Kolivand ${ }^{1 *}$, Hadi Kazemi ${ }^{1,2}$}

${ }^{1}$ Shefa Neuroscience Research Center, Khatam Alanbia Hospital, Tehran, Iran

${ }^{2}$ Pediatric Department, Medical Faculty, Shahed University, Tehran, Iran

\section{ABSTRACT}

Introduction: Covid-19 pandemic has created a worldwide emergency that poses a devastating threat to mental health, economic, and social indicators. Social distancing and quarantine have seriously damaged social relations. The quarantine can lead to socio-economic problems, such as long-term unemployment, job losses, and declining family incomes in many countries. Declining social relations and changing economic conditions can lead to serious crises, particularly psychological issues, in metropolitan areas. Hence, it is necessary to look at these aspects that have received less attention. Materials and Methods: In this study, the socio-economic aspects of COVID-19 disease in Tehran collected from 200,000 citizens based on qualitative indicators in the form of a questionnaire, and then the data were analyzed. Results: The results of this project showed that people's responses are very different depending on the type of job (private, government, informal, and self-employment). The type of employment relationship is decisive in answering questions, such as job loss during and after the corona pandemics, living standards, and reduced costs of luxury goods. Conclusion: In order to reduce the social risks, non-governmental organizations and the government should prepare and implement programs to ensure job security, create a desire to save, produce structured job opportunities, and develop skills.

Keywords:

1. COVID-19

2. Physical Distancing

3. Quarantine

*Corresponding Author: Pir Hossein Kolivand

Email:peirhossein@yahoo.com 


\section{تأثير كوويد-19 بر سلامت روان، مباحث اقتصادى اجتماعى و روابط اجتماعى در تهران: يكى مطالعئ يايلوت}

"يير حسين كوليوندا"، هادى كاظمى ז،

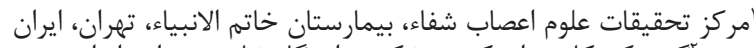

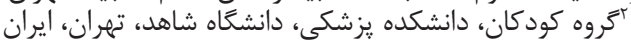

اطلاعات مقاله:

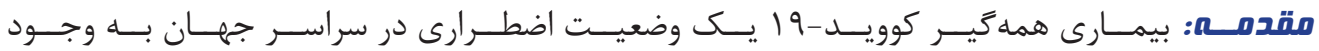

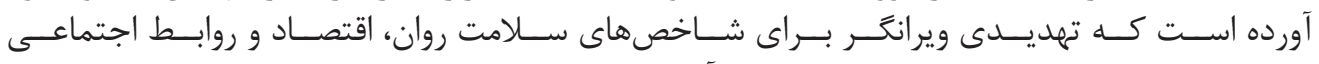

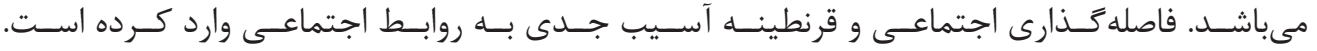

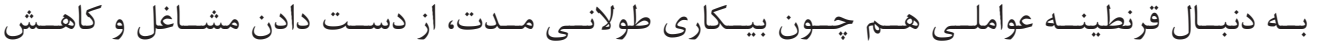

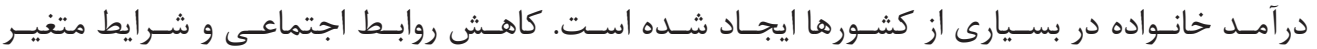

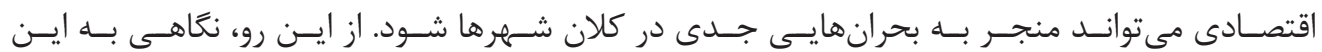

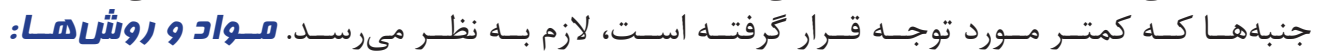

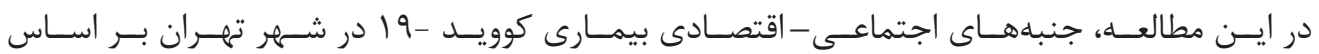

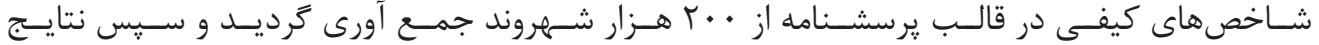

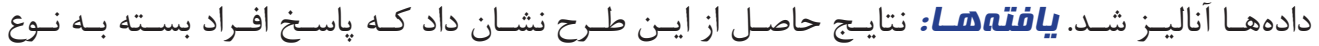

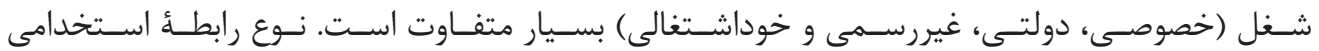

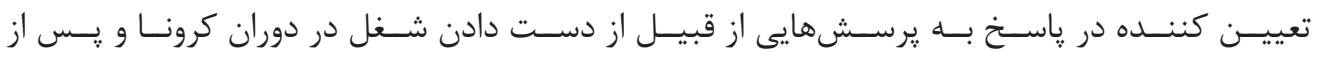

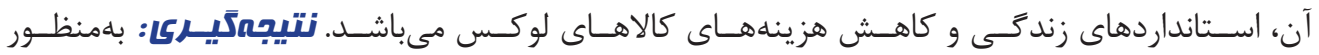

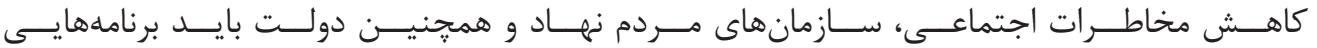

وازمهاى كليدى:

$19-19$ ب- فاصلة فيزيكى ب

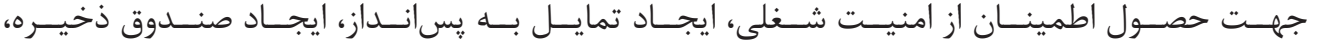

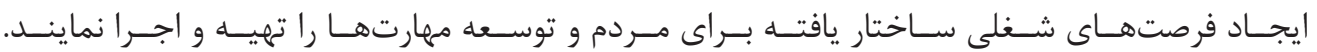

*نويسنده مسئول: ييرحسين كوليوند

يست الكترونيك: peirhossein@yahoo.com 


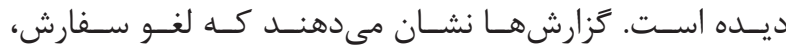

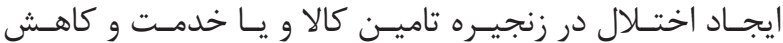

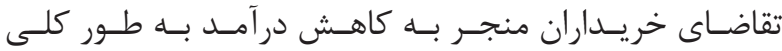

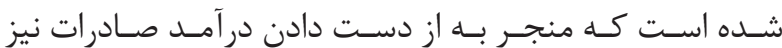

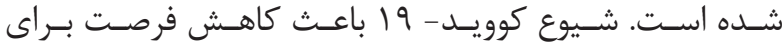

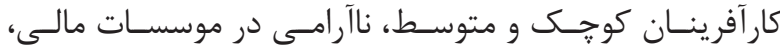

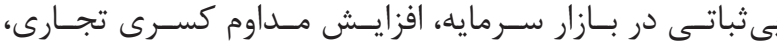

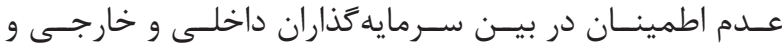

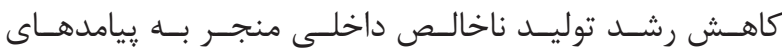

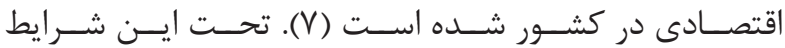

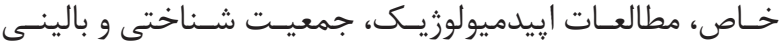

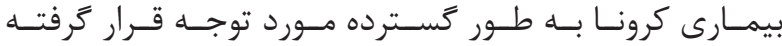

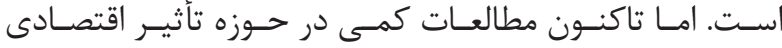

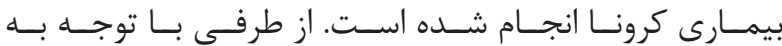

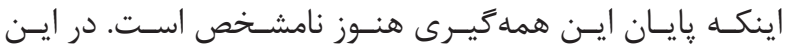

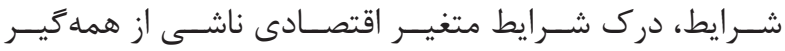

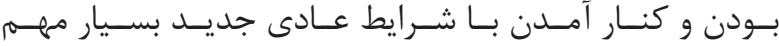

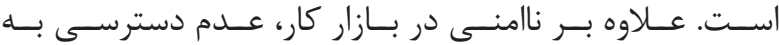

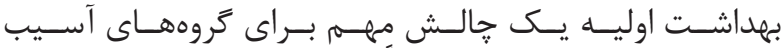

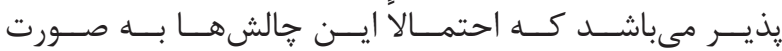

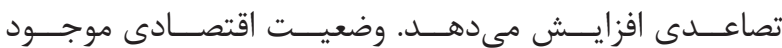

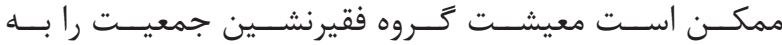

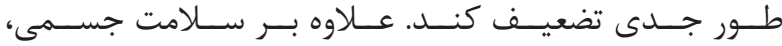

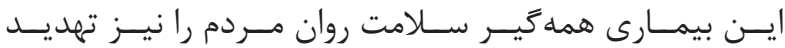

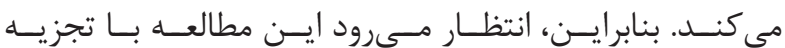

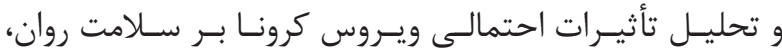

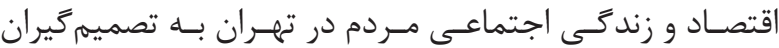

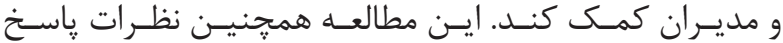

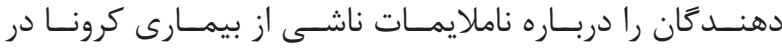

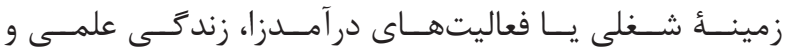

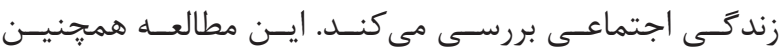

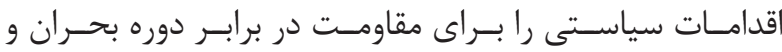

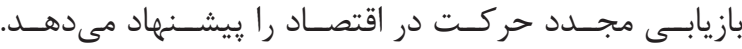

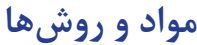

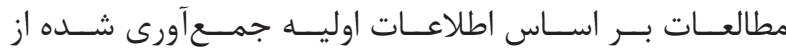

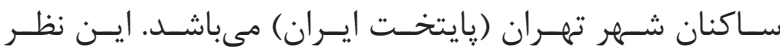

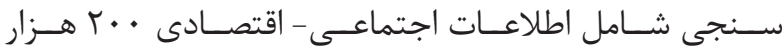

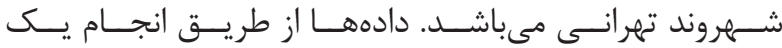

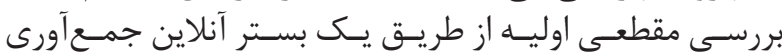

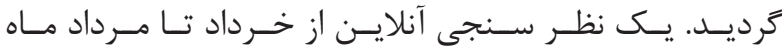

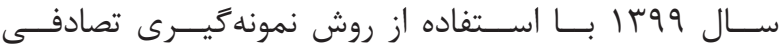

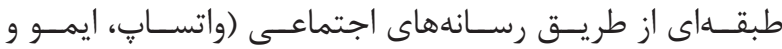

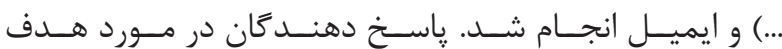

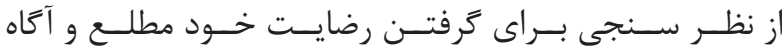

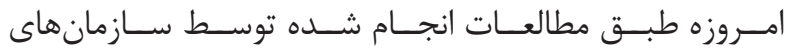

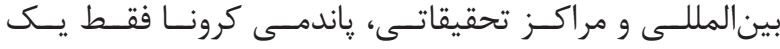

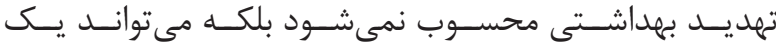

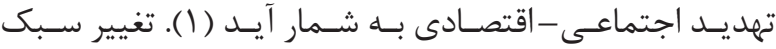

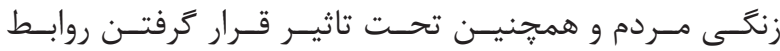

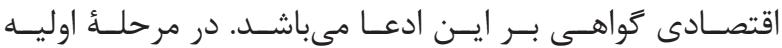

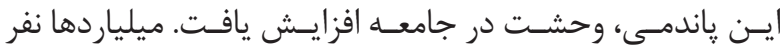

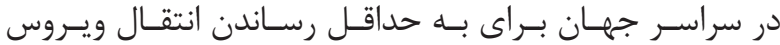

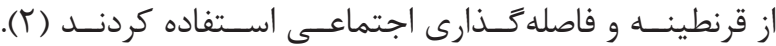

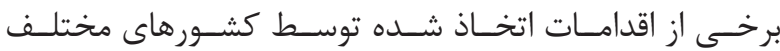

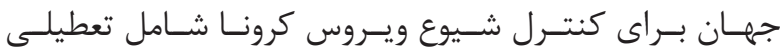

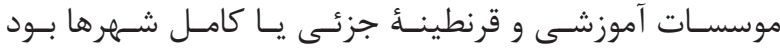

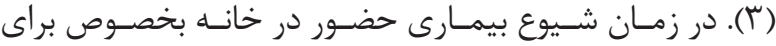

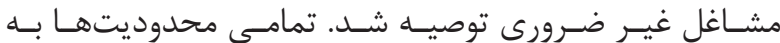

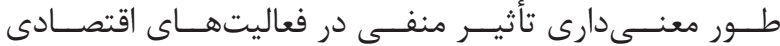

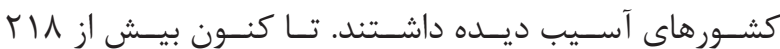

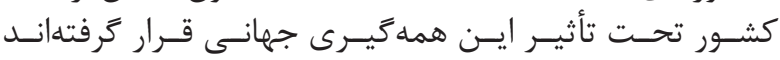

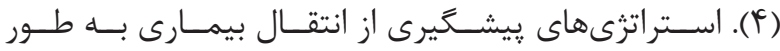

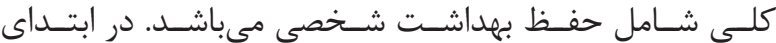

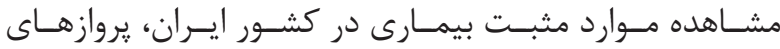

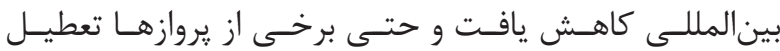

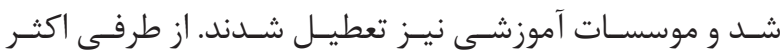

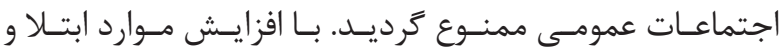

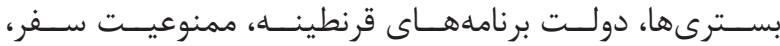

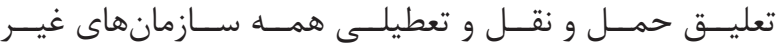

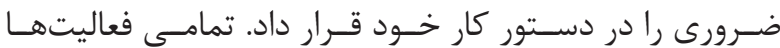

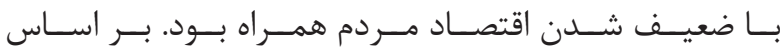

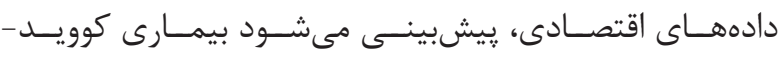

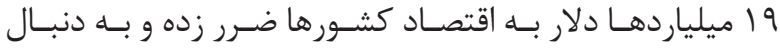

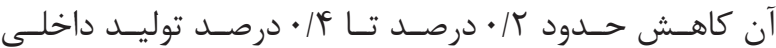

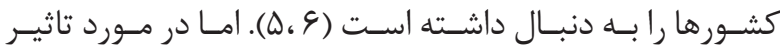

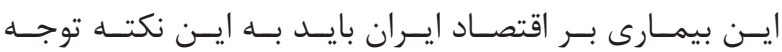

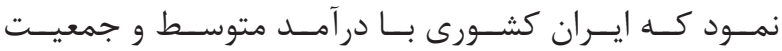

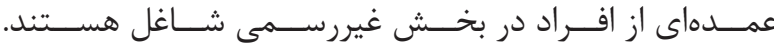

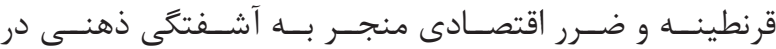

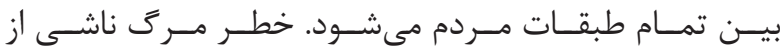

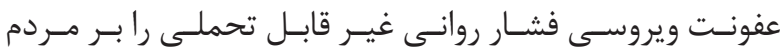

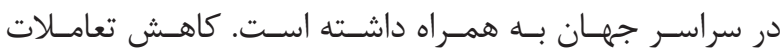

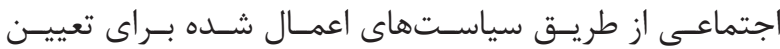

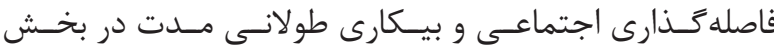

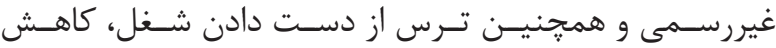

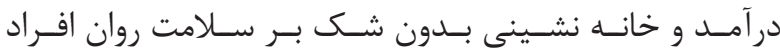

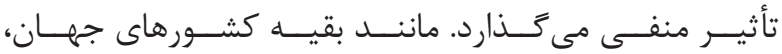

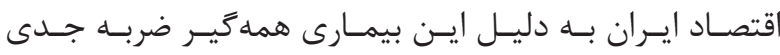




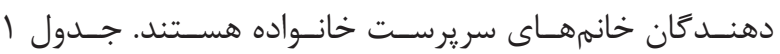

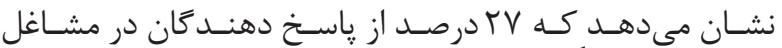

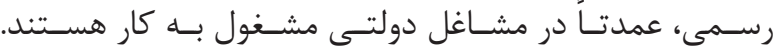

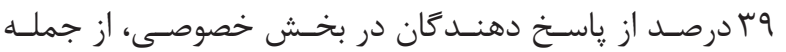

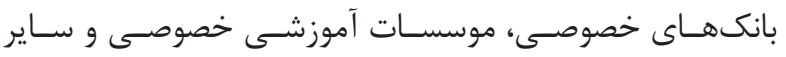

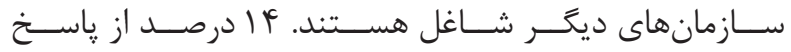

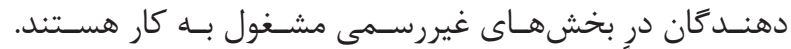

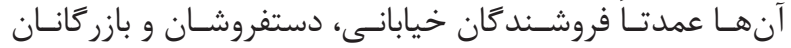

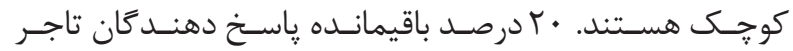

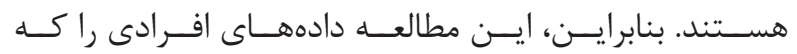

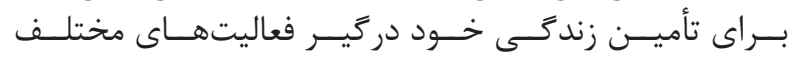

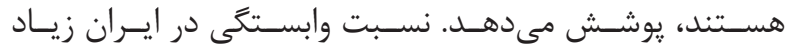

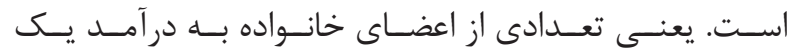

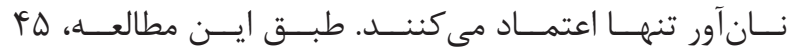

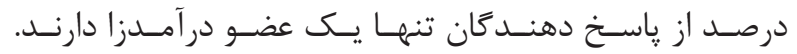

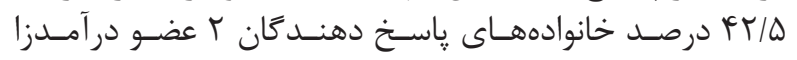

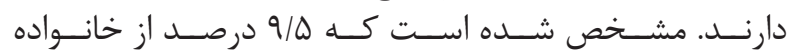

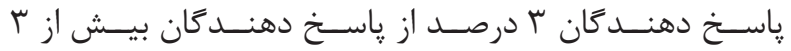

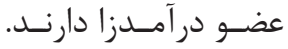

تاثير اقدامات انجام شده بر رفتار مردم

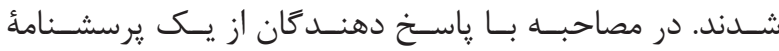

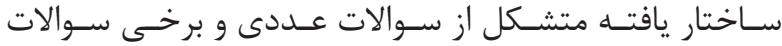

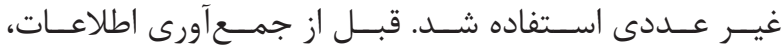

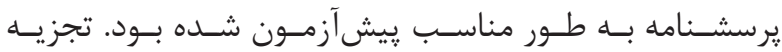

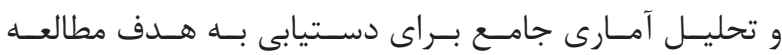

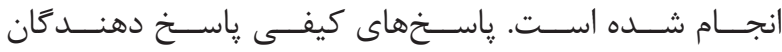

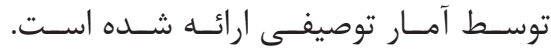

يافته ها

اطلاعات دموَّرافيك

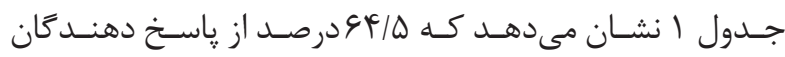

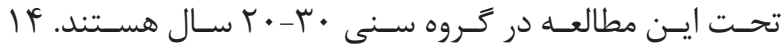
درصـد از ياسـخ دهنــد

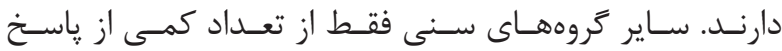

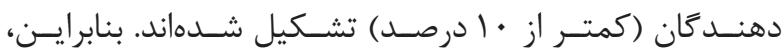

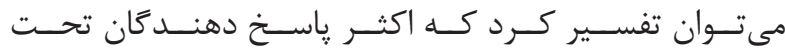

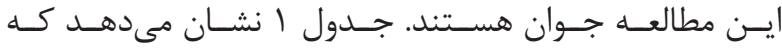

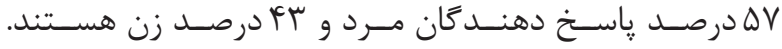

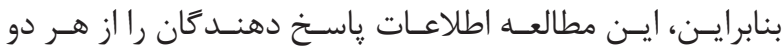

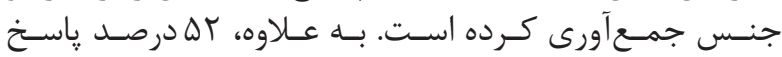

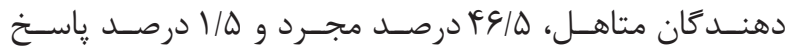

جدول ا- توزيع جمعيتى ياسخ دهندكان

\begin{tabular}{|c|c|c|}
\hline تروه & درصد & شاخصها \\
\hline كمتر يا مساوى ·r & $N / \Delta$ & \multirow{5}{*}{ سن } \\
\hline r) & $+\varphi / \Delta$ & \\
\hline ri-r. & if & \\
\hline$|f|-\Delta$. & $\checkmark$ & \\
\hline بالاى •ט & 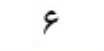 & \\
\hline 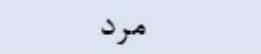 & $\Delta V$ & \multirow{2}{*}{ جنسيت } \\
\hline زن & Ft & \\
\hline متاهل & $\Delta r$ & \multirow{2}{*}{ وضعيت تاهل } \\
\hline مجرد & $F \& / \Delta$ & \\
\hline غيره & $1 / 0$ & \multirow{5}{*}{ نوع رابطه شغلى } \\
\hline بخش دولتى & $r V$ & \\
\hline بخش خصوصى & एq & \\
\hline بخش غيررسمى & If & \\
\hline بخش تجارى & $r \cdot$ & \\
\hline 1 & $F \Delta$ & \multirow{4}{*}{ تعداد اعضاى در آمدزا در خانواده } \\
\hline$r$ & $F T / D$ & \\
\hline r & $9 / 0$ & \\
\hline بيشتر ازيّي & $r$ & \\
\hline
\end{tabular}




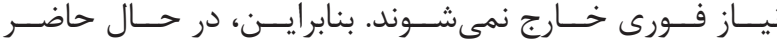

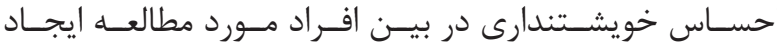

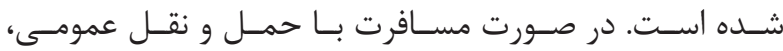

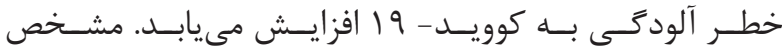

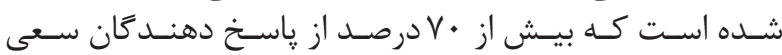

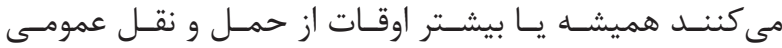

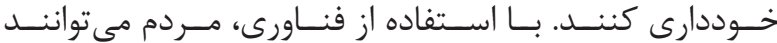

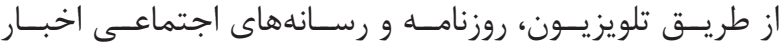

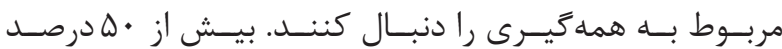

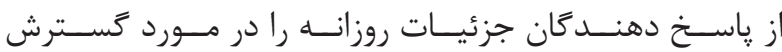

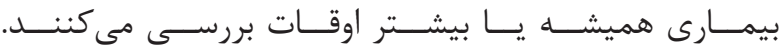

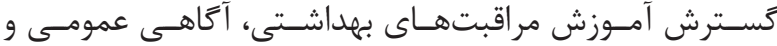

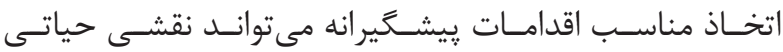

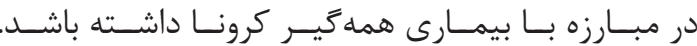

\section{ناثير ات منفى كرونا بر مشاغل و رفاه}

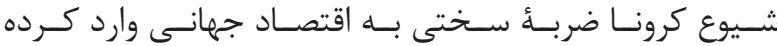

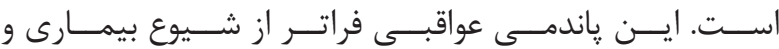

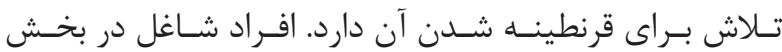

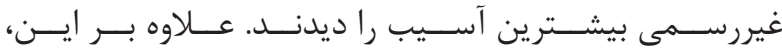

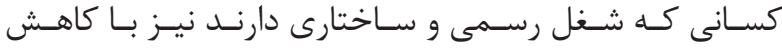

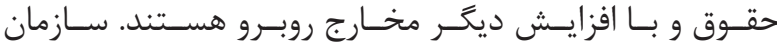

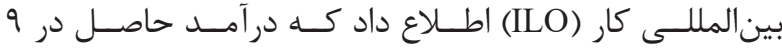

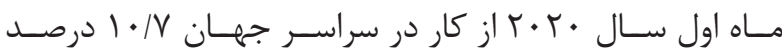

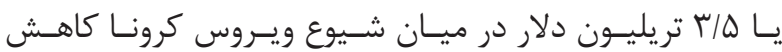

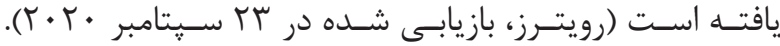

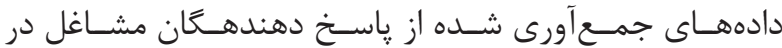

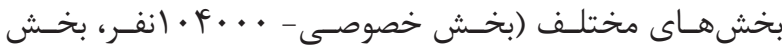

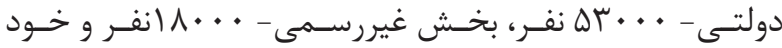

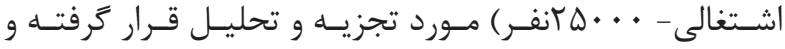

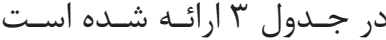

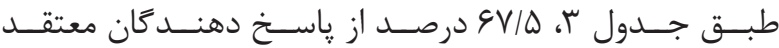

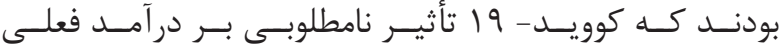

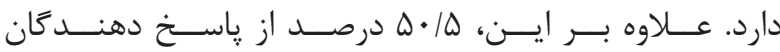

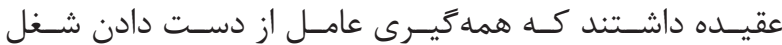

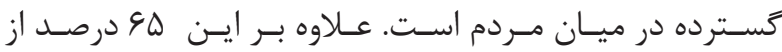

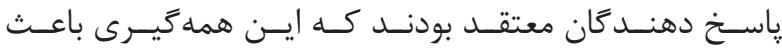

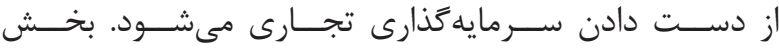

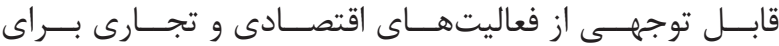

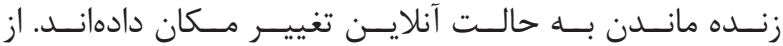

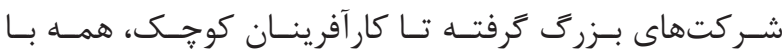

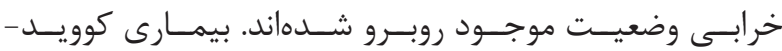

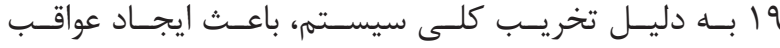

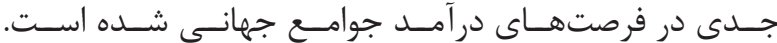

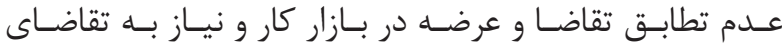

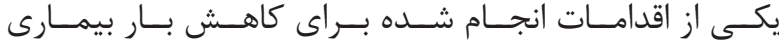

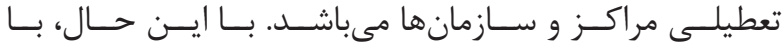

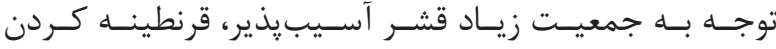

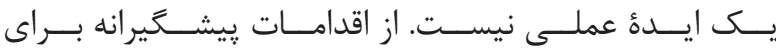

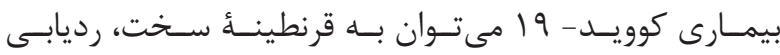

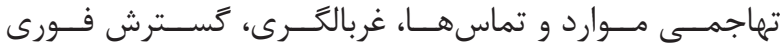

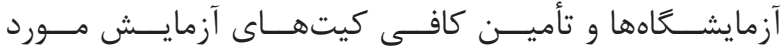

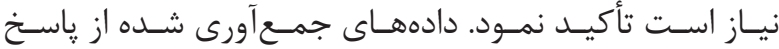

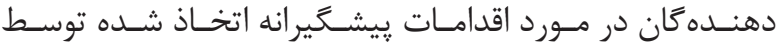

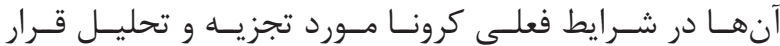

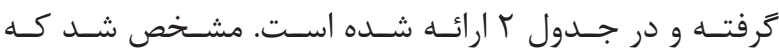

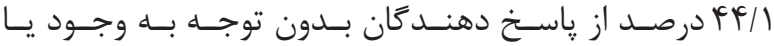

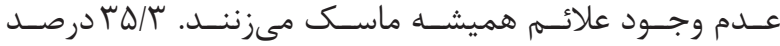

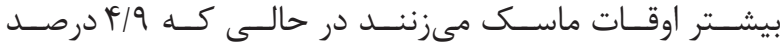

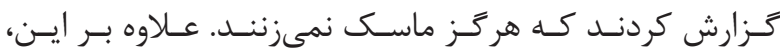

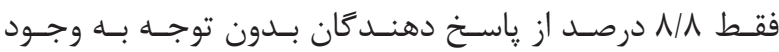

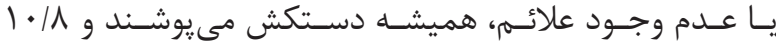

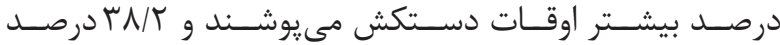

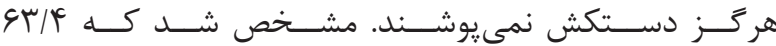

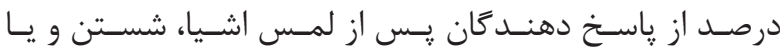

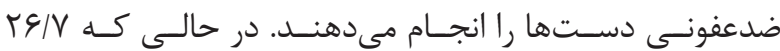

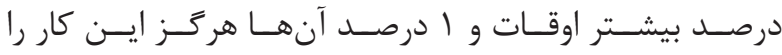

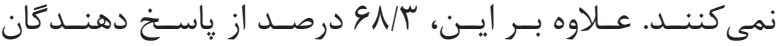

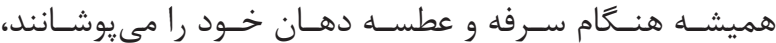

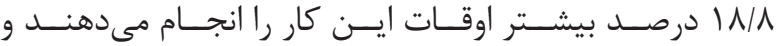

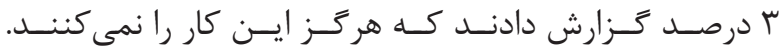

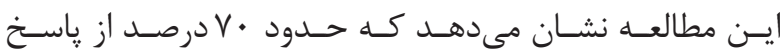

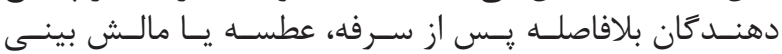

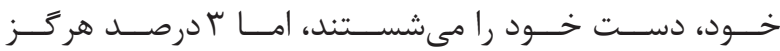

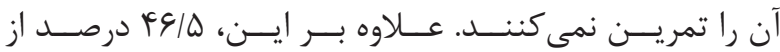

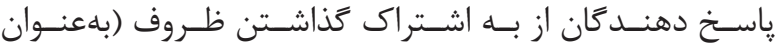

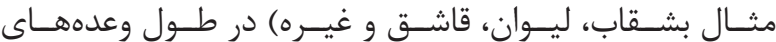

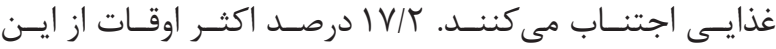

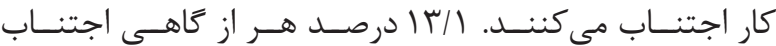

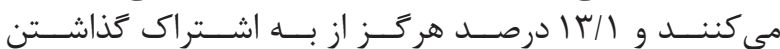

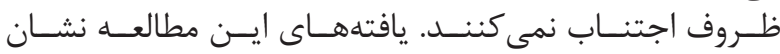

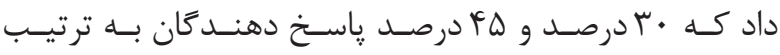

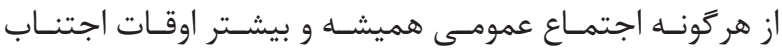

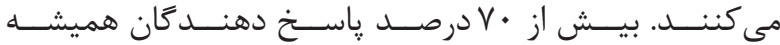

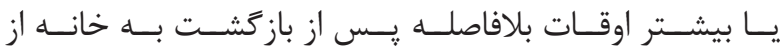

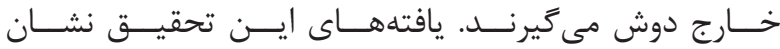

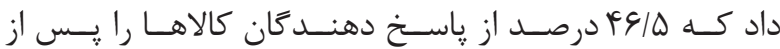

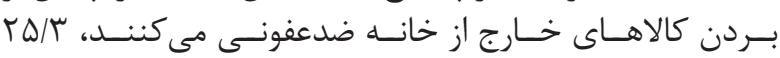

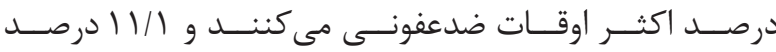

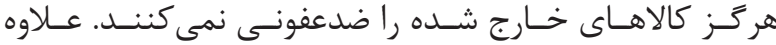

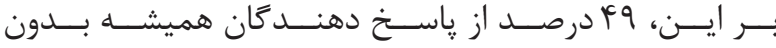


جدول r- اقدامات پيشكَيرانه اتخاذ شده توسط جمعيت مطالعاتى در وضعيت فعلى كوويد- 19

\begin{tabular}{|c|c|c|c|}
\hline درصد & هياسخ & اقدامات احتياطى & رديف \\
\hline$F+11$ & هميشه & \multirow{5}{*}{ استفاده از ماسك صرف نظر از وجود يا عدم وجود علاثم } & \multirow{5}{*}{1} \\
\hline$r \Delta / r$ & بيشتر اوقات & & \\
\hline $11 / \lambda$ & مثاهى اوقات & & \\
\hline$r / 9$ & مَاه و بيُخاه & & \\
\hline$f / 9$ & هيجوقت & & \\
\hline NA & هميشه & \multirow{5}{*}{ يوشيدن ستكث بندن توجه به وجود يا عدم وجود علاثم } & \multirow{5}{*}{$r$} \\
\hline $1 \cdot / 1$ & بيشتر اوقات & & \\
\hline$r \mid / 9$ & تحاهى اوقات & & \\
\hline$r \cdot / 9$ & تماه و بيمّاه & & \\
\hline TNT & هيجرقت & & \\
\hline $9 \pi / 4$ & هميشه & \multirow{5}{*}{ 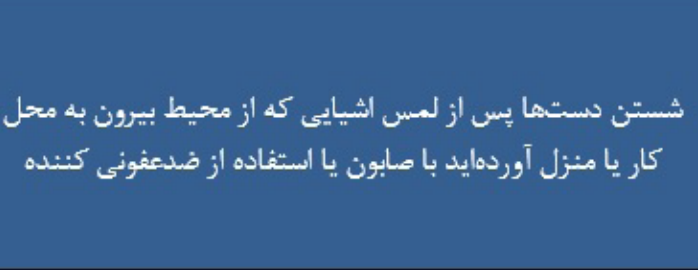 } & \multirow{5}{*}{$r$} \\
\hline$r \& / V$ & بيشتر اوقات & & \\
\hline$V / 9$ & مَاهى اوقات & & \\
\hline 1 & 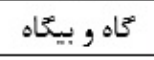 & & \\
\hline 1 & هيعوقت & & \\
\hline GNT & هميشه & \multirow{5}{*}{ بوشاندن دهان هئَّام سرفه و عطسه } & \multirow{5}{*}{$\mathbf{F}$} \\
\hline WN & بيشتر اوقات & & \\
\hline$V / 9$ & تماهى اوقات & & \\
\hline$r$ & متاه و بئَّاه & & \\
\hline$r$ & هيعرقت & & \\
\hline 99 & ميشه & \multirow{5}{*}{ شستن دستها بالفاصله بعد از سرفه، عطسه يا مالش بينى } & \multirow{5}{*}{$\Delta$} \\
\hline 19 & بيشتر اوقات & & \\
\hline V & تماهى اوقات & & \\
\hline r & 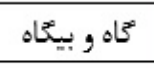 & & \\
\hline$r$ & هيتجرقت & & \\
\hline$+9 / 0$ & هميشه & \multirow{5}{*}{ 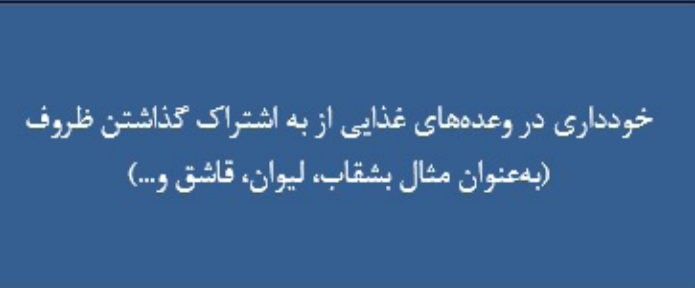 } & \multirow{5}{*}{9} \\
\hline IV/T & بيشتر اوقات & & \\
\hline $1+/ 1$ & ماهى لوقات & & \\
\hline $\mid \pi / 1$ & 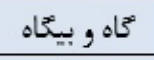 & & \\
\hline$|\pi / 1|$ & هيجرقت & & \\
\hline$r$. & مميشه & \multirow{5}{*}{ خوددارى از هر نوع اجتماع عمومى } & \multirow{5}{*}{$\mathrm{v}$} \\
\hline$f \Delta$ & 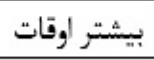 & & \\
\hline 11 & تخاهى لوقات & & \\
\hline$f$ & متاه و بيتّاه & & \\
\hline r & هيترقت & & \\
\hline$\Delta r$ & مميشه & \multirow{5}{*}{ دوش ثرفتن بلافاصله بِس از بازٌْشت از محيط بيرون از منزل } & \multirow{5}{*}{$\wedge$} \\
\hline$r$. & بيشتر اوقات & & \\
\hline if & كماهى اوقات & & \\
\hline 9 & 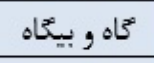 & & \\
\hline$F$ & هيعزوقت & & \\
\hline
\end{tabular}



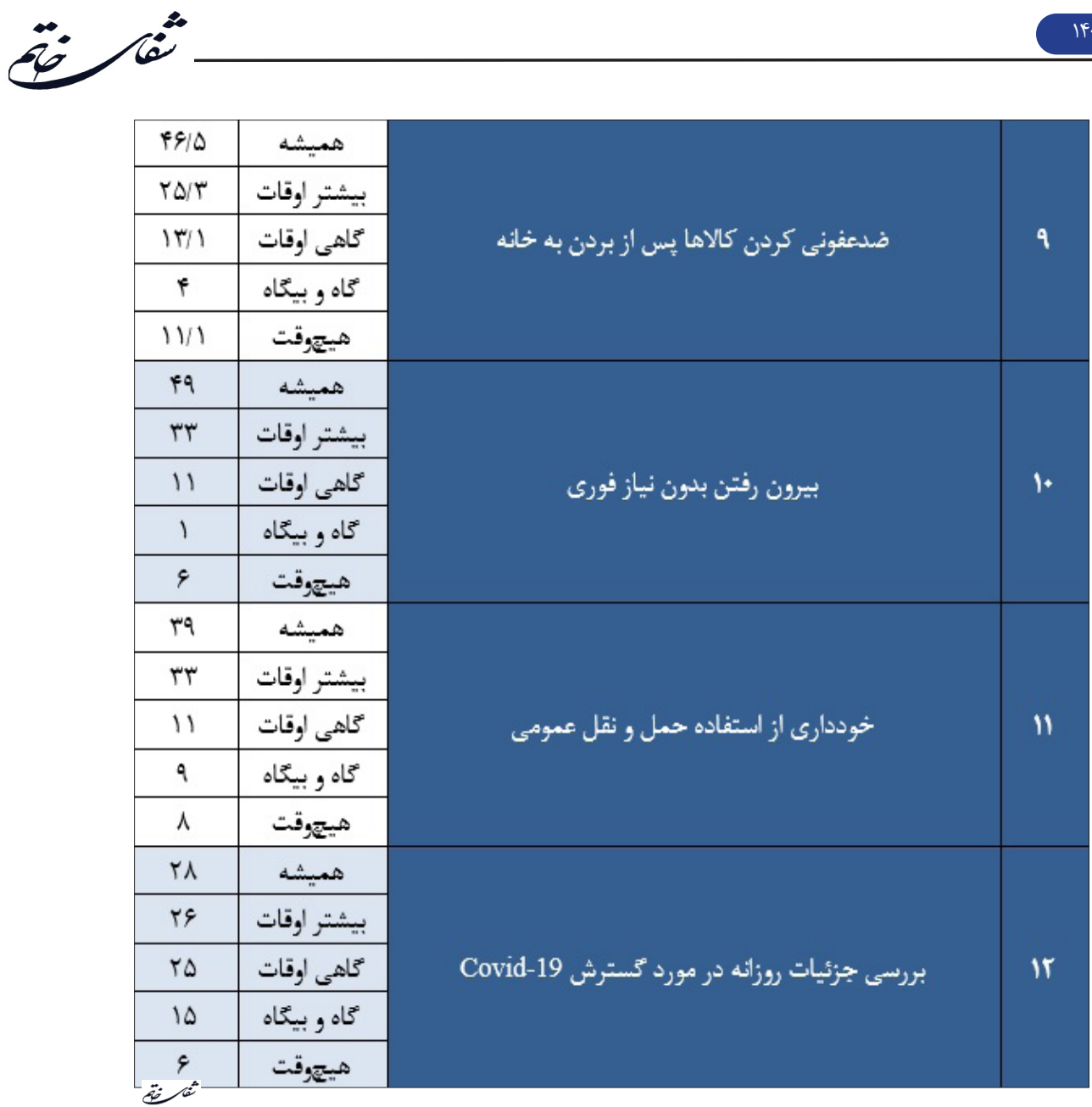

جدول r- تأثيرات منفى ناشى از كرونا

\begin{tabular}{|c|c|c|c|c|c|c|c|c|}
\hline \multicolumn{9}{|c|}{ وضعيت شغلى } \\
\hline ضريب كا & درصد & جمع & خويش ثرما & بخش غيررسمى & عمومى & خصوصى & عقيده & ويرتَّىها \\
\hline $\mid \gamma / \pi \cdots$ & $9 V / 0$ & $1 T \Delta$ & $r \Delta$ & if & rq & $9 V$ & بله & \multirow{3}{*}{ تأثير مثفى بر درآمد } \\
\hline \multirow[t]{2}{*}{$\cdot / \cdots 1$} & $r T / \Delta$ & 90 & $\cdots$ & $\cdot f$ & tf & rr & خير & \\
\hline & $1 \cdots$ & $r \cdots$ & ro & 11 & or & $1 \cdot f$ & جمع & \\
\hline $9 / 991$ & $\Delta \cdot / \Delta$ & 1.1 & 1. & iv & $\cdots$ & Vf & بله & \multirow{3}{*}{ تأثير در از دست دادن شغل } \\
\hline \multirow[t]{2}{*}{$\cdot 1 \cdot \mathrm{Vt}$} & $49 / 0$ & 99 & 10 & 1 & $\Delta T$ & $r$. & خير & \\
\hline & $1 \cdots$ & $r \cdots$ & ro & 11 & $\Delta r$ & $1 . f$ & جمع & \\
\hline IDITF. & 90 & 15. & rt & if & re & $9 \mathrm{~V}$ & بله & \multirow{3}{*}{ تأثير بر ضرر در تجارت } \\
\hline \multirow[t]{2}{*}{$\cdot \mu r$} & ro & v. & r & $\cdots$ & tr & rv & خير & \\
\hline & $1 \cdots$ & $r \cdots$ & ro & 11 & $\Delta r$ & $1 . f$ & جمع & \\
\hline IDITF. & 9N/O & $1 \mathrm{IrV}$ & $4 t$ & if & tr & 91 & بله & \multirow{3}{*}{ خطر از دست دادن شغل در آيثده } \\
\hline \multirow[t]{2}{*}{$\cdot \mu t$} & $r / \Delta$ & Gr & .4 & $\cdot f$ & rI & rq & خير & \\
\hline & $1 \ldots$ & $r \cdots$ & ro & 11 & or & $1 . f$ & جمع & \\
\hline$\Delta / T I \Lambda$ & $9 \mathrm{~V}$ & $1 T F$ & 19 & 10 & $r v$ & 95 & بله & \multirow{3}{*}{ كاهش در هزينهها } \\
\hline \multirow[t]{2}{*}{$\cdot / 1 \Delta \mathrm{V}$} & r & 98 & .9 & $\cdot 4$ & 18 & fi & خير & \\
\hline & $1 \ldots$ & $r \cdot$ & ro & 11 & or & $1 \cdot f$ & جمع & \\
\hline th/TVE & $9 \mathrm{~V}$ & ITf & זr & 19 & rq & $\Delta f$ & بله & \multirow{3}{*}{ تأثير سو بر سطح زندئى } \\
\hline \multirow[t]{2}{*}{$\cdot / \cdots$} & rT & 98 & .4 & .4 & if & $\Delta$. & خير & \\
\hline & $1 \cdots$ & $r \cdots$ & ro & 11 & $\Delta r$ & $1 \cdot f$ & جمع & \\
\hline$I \cdot / V \cdot V A$ & $V \Delta / \Delta$ & 101 & ro & 10 & rᄉ & VT & بله & \multirow{3}{*}{ كاهش هزينههاى كالاهاى لوكس } \\
\hline $.1 \cdot 14$ & $T f / \Delta$ & 49 & $\cdots$ & $\cdot r$ & 10 & r & خير & \\
\hline - & $1 \cdots$ & $r \cdots$ & ro & 11 & $\Delta r$ & $1 \cdot f$ & جمع & \\
\hline
\end{tabular}




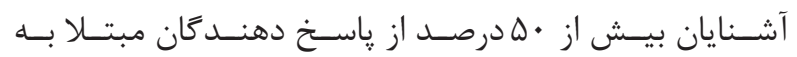

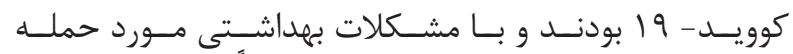

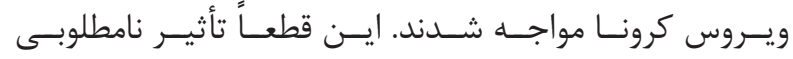

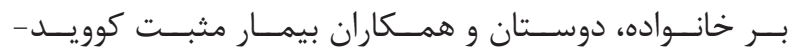

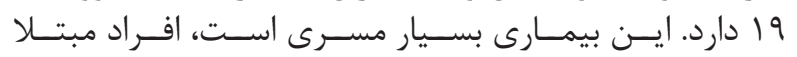

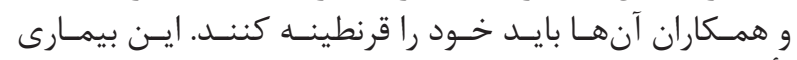

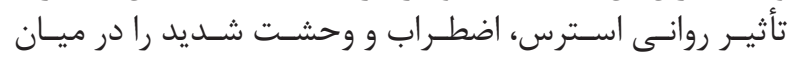

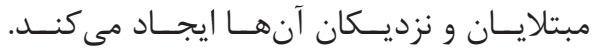

\section{نكَرانى از تاخير هاى تحصيلى}

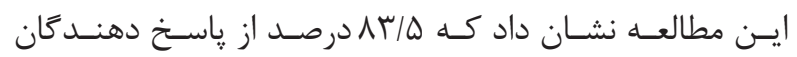

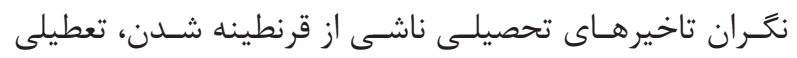

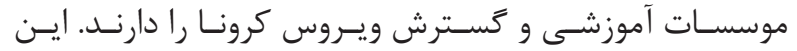

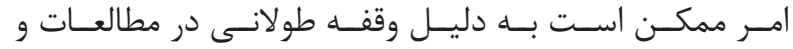

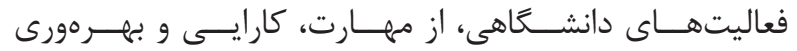

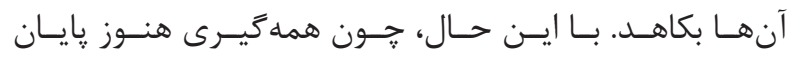

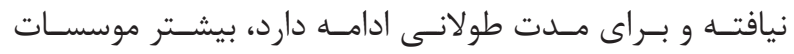

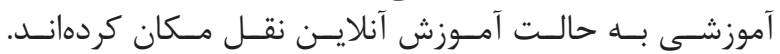

\section{نغر انى از بيكار بودن}

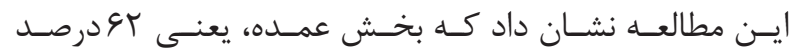

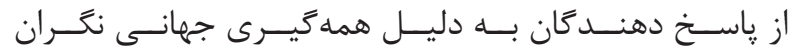

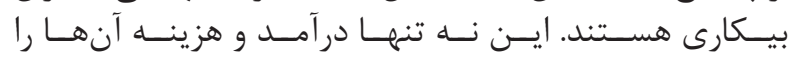

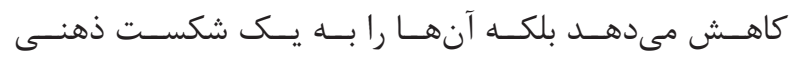

$$
\text { ســوق مى دهــــد. }
$$

نكرانى از دست دادن ثبات بلند مدت در تجارت

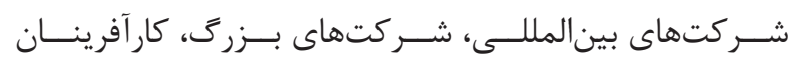

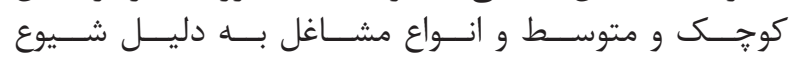

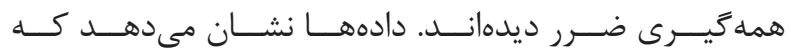

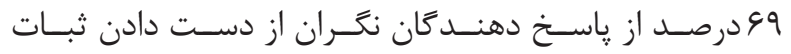

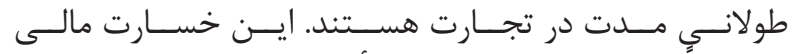

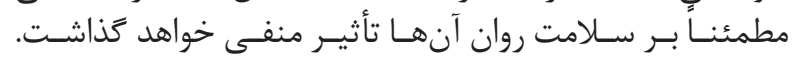

نكَرانى از خطر سلامتى سالمندان در خانواده

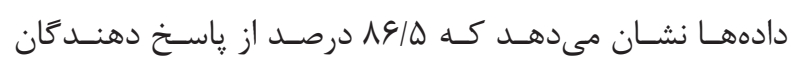

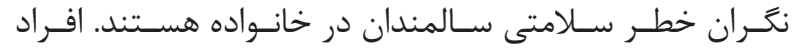

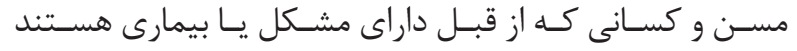

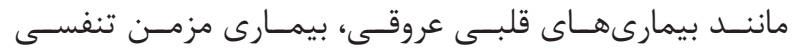

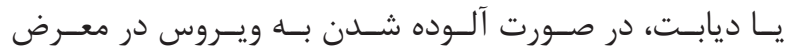

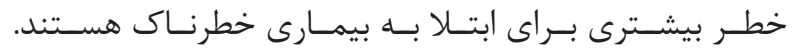

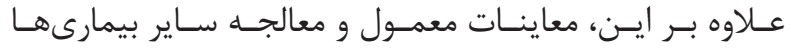

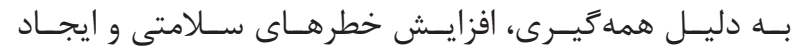

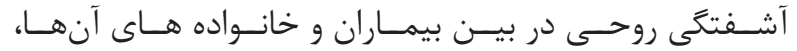

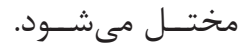

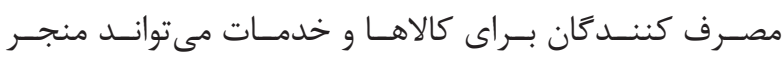

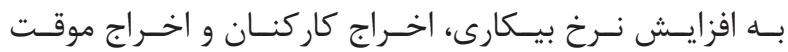

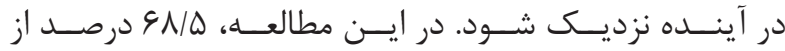

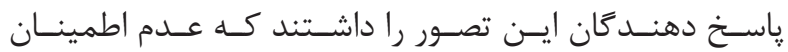

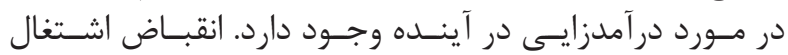

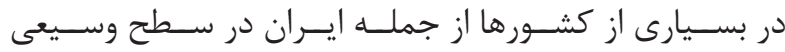

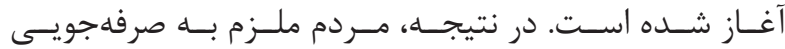

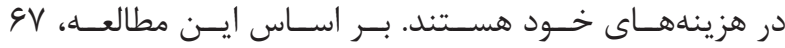

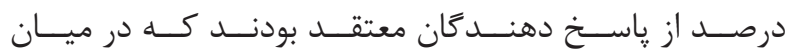

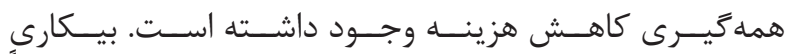

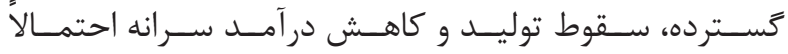

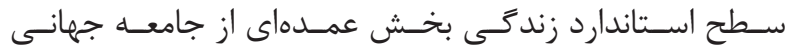

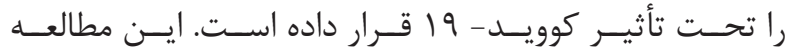

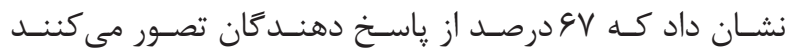

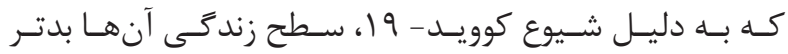

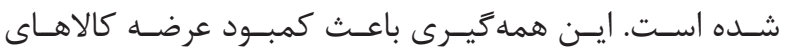

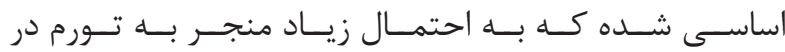

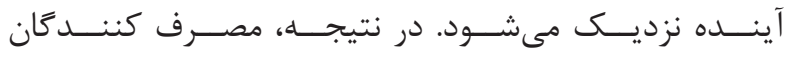

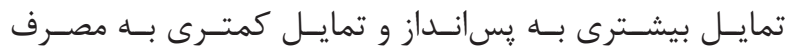

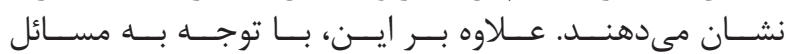

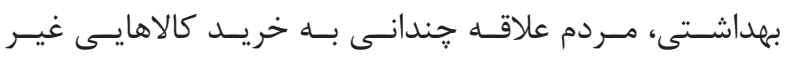

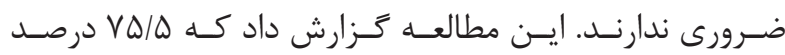

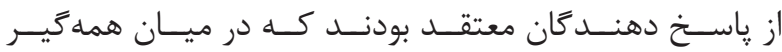

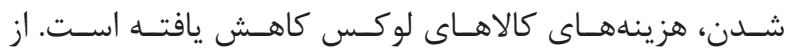

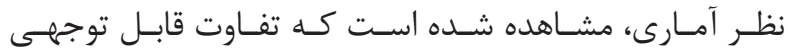

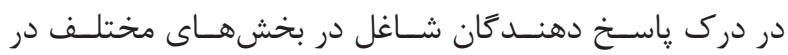

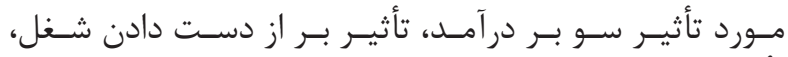

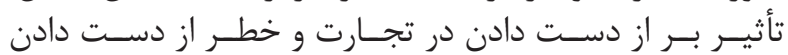

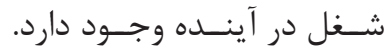
تأثير كوويد- 19 بر سلامت روان

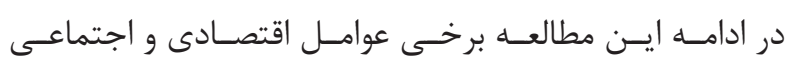

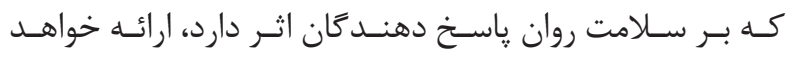

در آمد خانواده ثابت

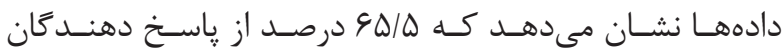

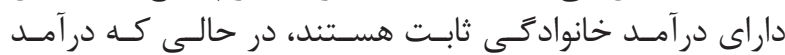

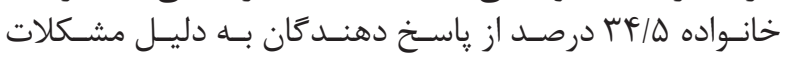

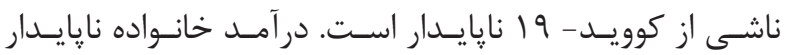

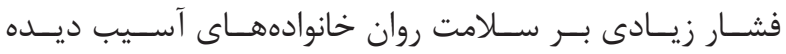

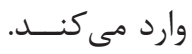

\section{مواجهه يا ابتلا به كوويد- 19}

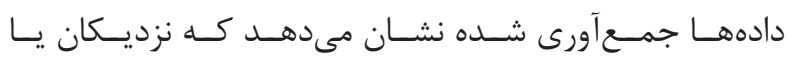




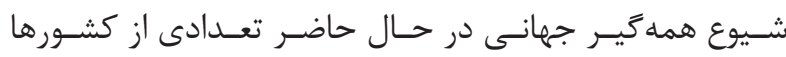

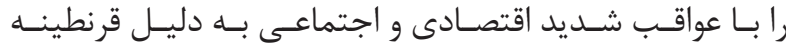

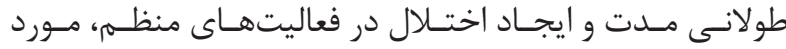

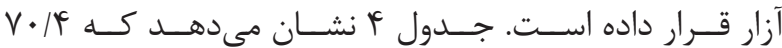

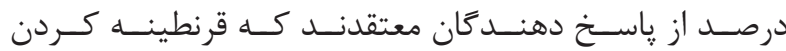

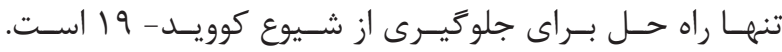

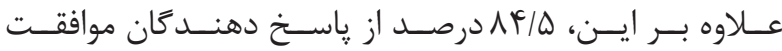

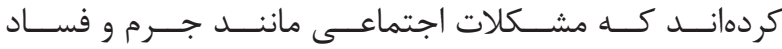

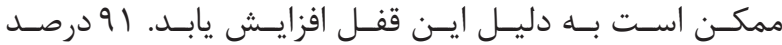

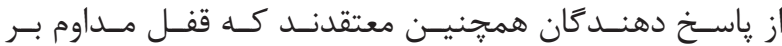

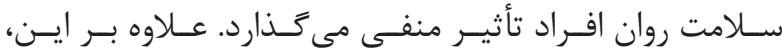

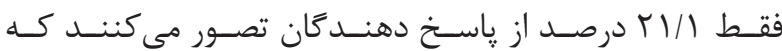

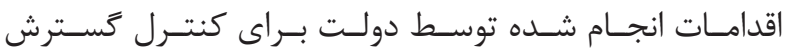

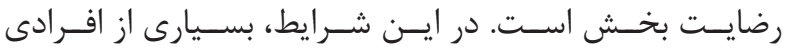

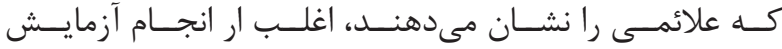

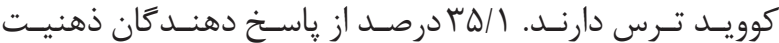

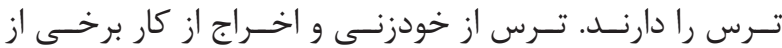

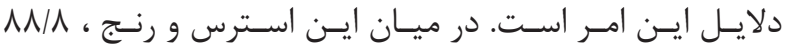

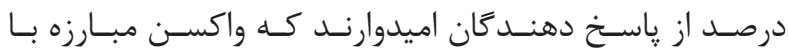

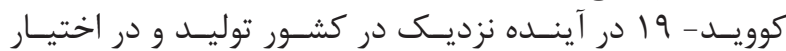

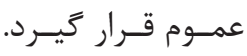

\section{نغرانى از آموزش و آينده كودكان}

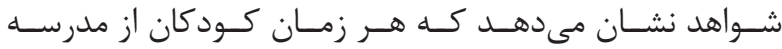

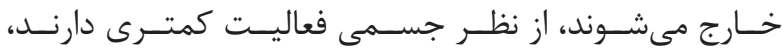

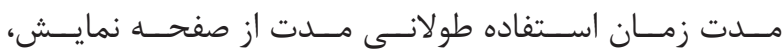

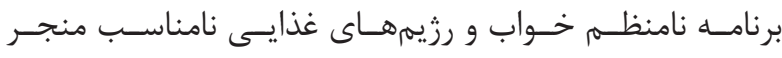

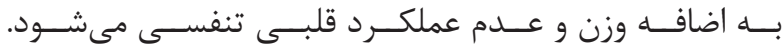

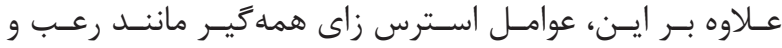

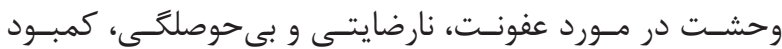

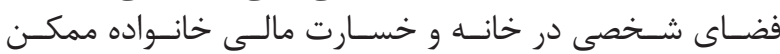

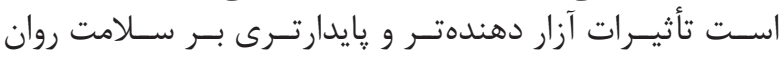

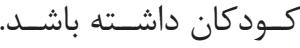

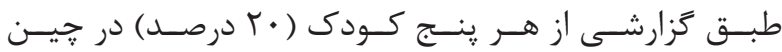

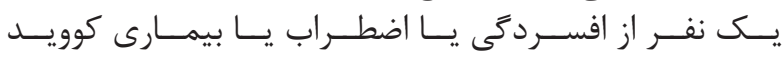

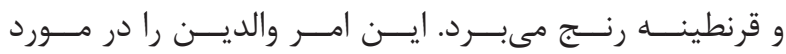

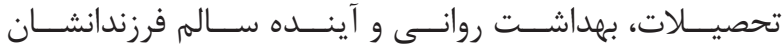

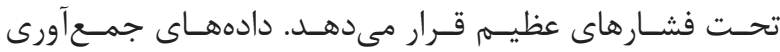

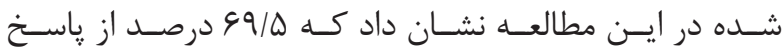

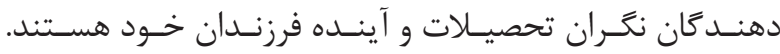

استيگماى كوويد- 19 و قرنظينه

جدول F - درك در مورد قرنطينه، تست كرونا و واكسن

\begin{tabular}{|c|c|c|}
\hline خير & بله & برداشتها \\
\hline$r q / 4$ & $V \cdot / f$ & تعطيلى تنها راه حل براى جلوكيرى از شيوع Covid-19 است. \\
\hline $10 / \Delta$ & $\Delta F / \Delta$ & قرنطينه به علت Covid-19 ممكن است منجر به مشكلات اجتماعى مانند جرم و فساد شود. \\
\hline 9 & 91 & قرنطينه مستمر تأثير نامطلوبى بر سلامت روان مردم خواهد داشت. \\
\hline$V \wedge / 9$ & $r \mid / l$ & اقداماتى كه دولت براى كنترل انتشار انجام داده رضايت بخش است. \\
\hline$q 4 / 9$ & $r \Delta / l$ & اخر علائم بالينى ابتلاء به Covid-19 را داشتيد، آيا ازتست و آزمايشCOvid-19 مىترسيد. \\
\hline $11 / 4$ & $\Lambda \mathrm{N} / \Lambda$ & آيا شما اميدوار هستيد كه در آينده نزديك واكسنى براى مبارزه با Covid-19 توسط دانشمندان داخلى توليد و مورد استفاده قرار گيرد. \\
\hline
\end{tabular}

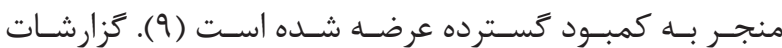

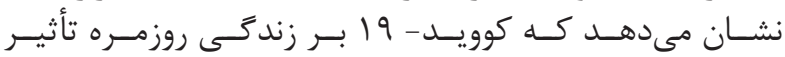

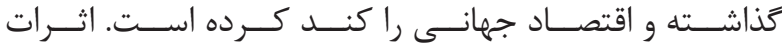

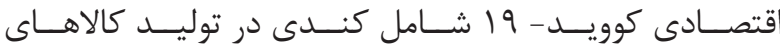

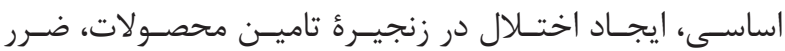

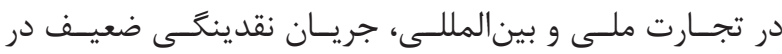

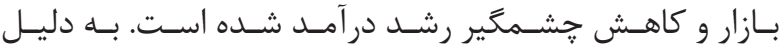

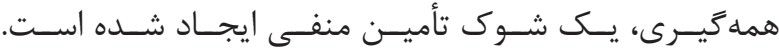

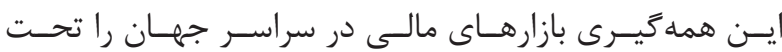

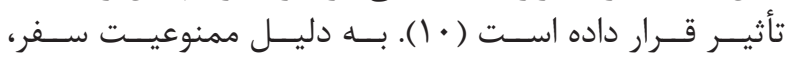

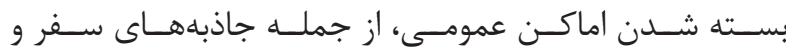

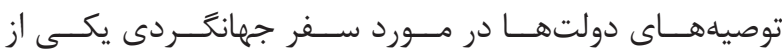

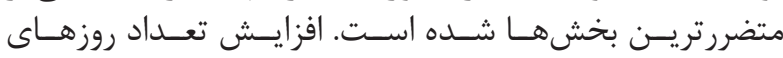

بحث و نتيجهَ

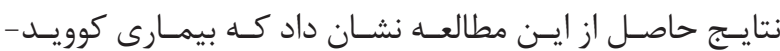

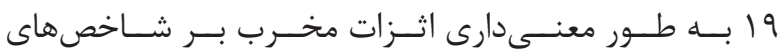

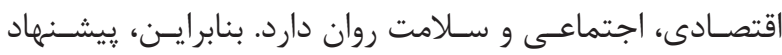

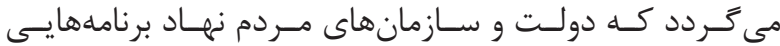

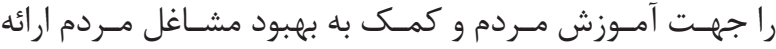

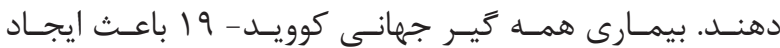

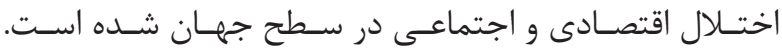

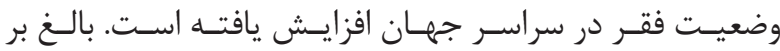

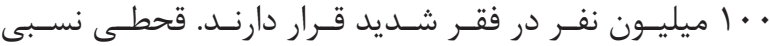

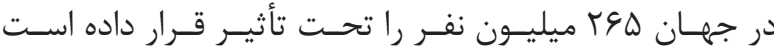

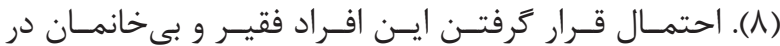

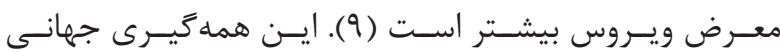




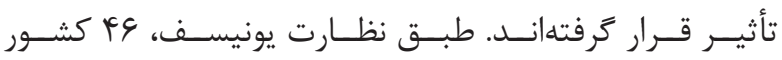

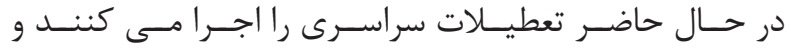


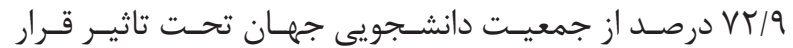

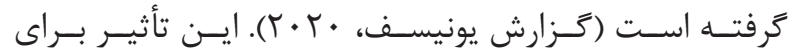

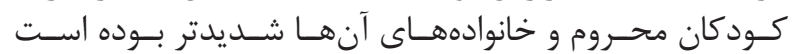

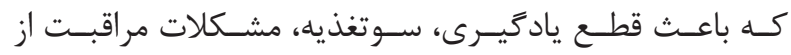

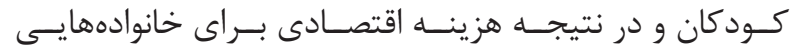

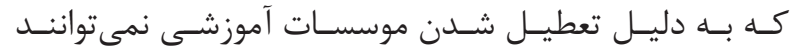

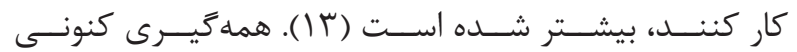

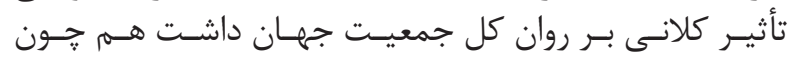

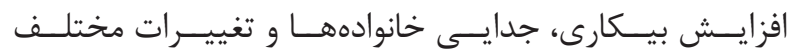

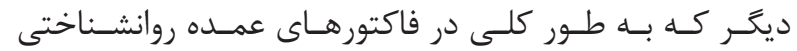

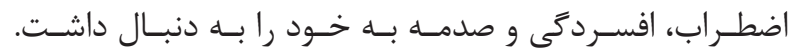

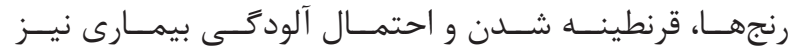

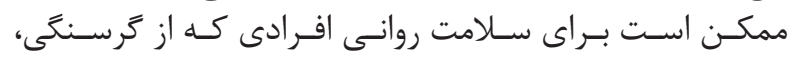

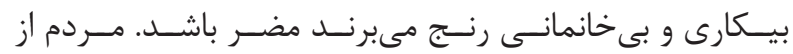

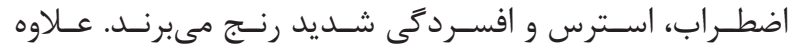

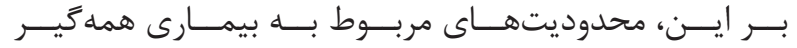

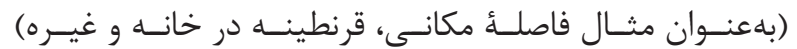

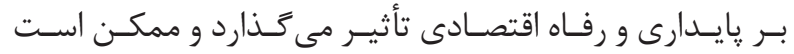

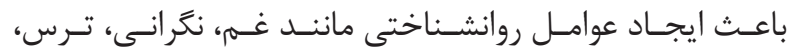

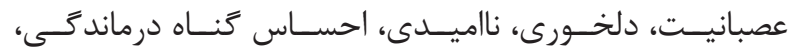

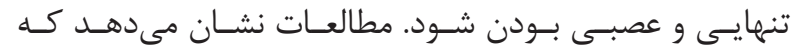

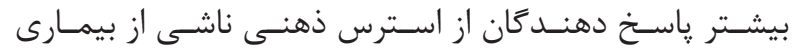

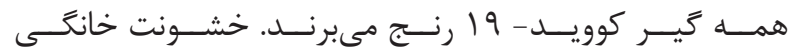

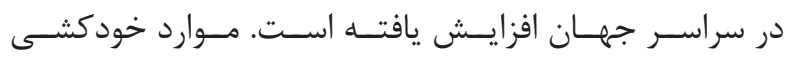

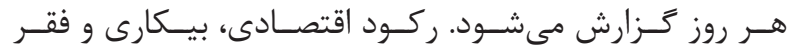

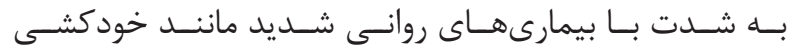

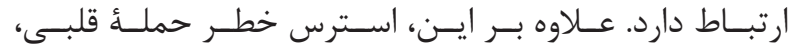

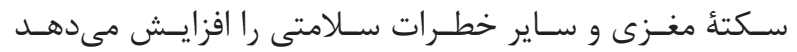

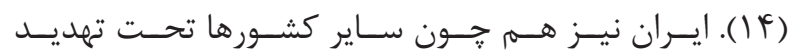

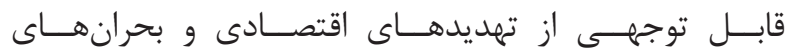

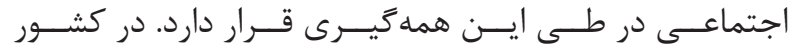

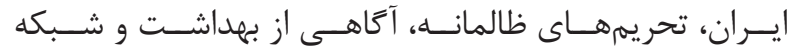

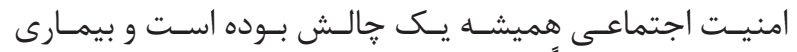

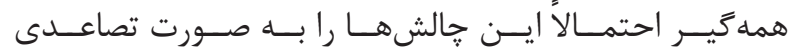

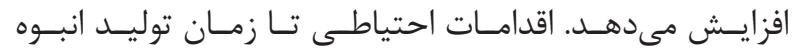

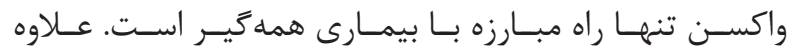

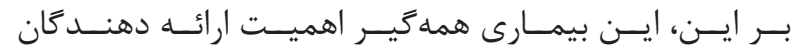

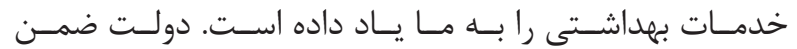

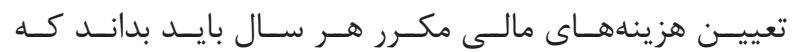

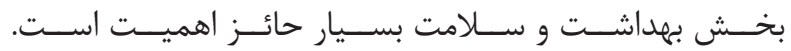

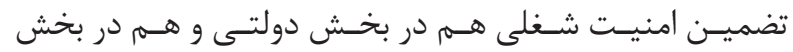

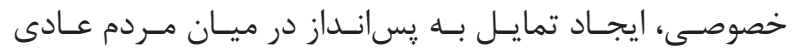

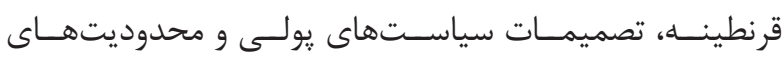

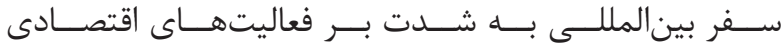

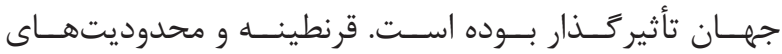

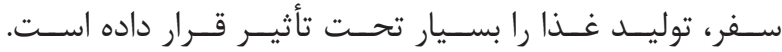

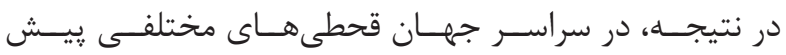

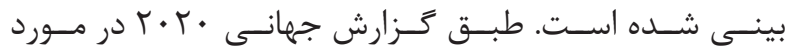

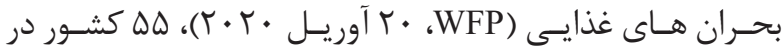

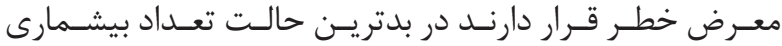

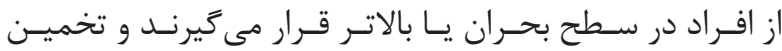

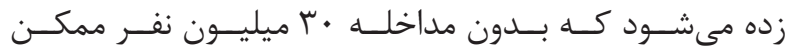

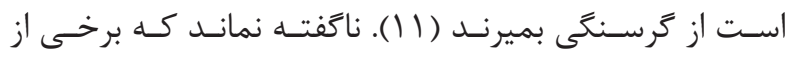

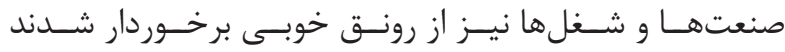

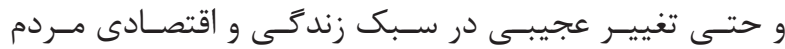

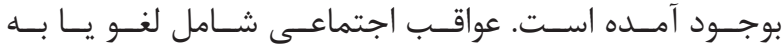

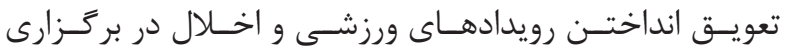

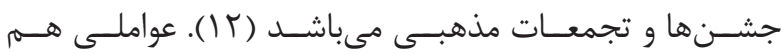

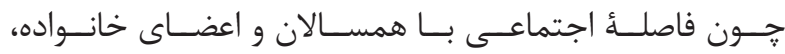

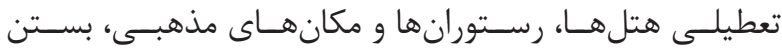

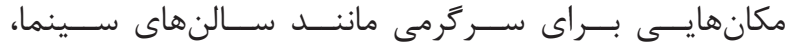

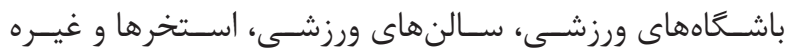

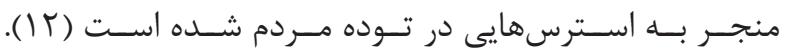

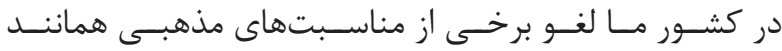

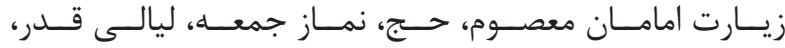

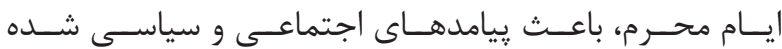

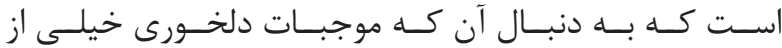

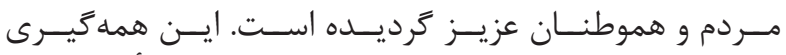

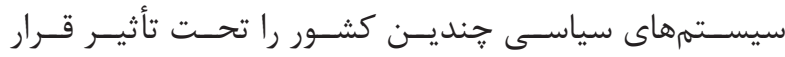

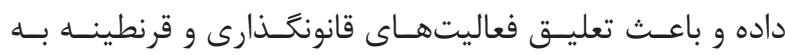

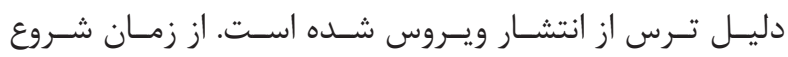

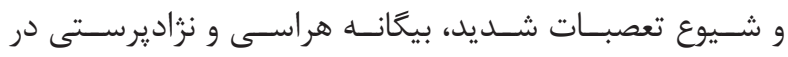

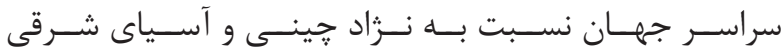

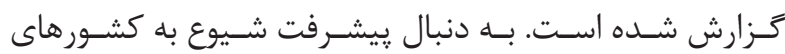

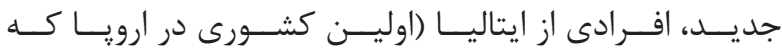

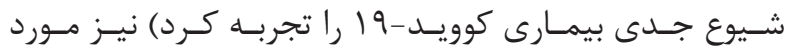

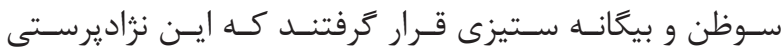

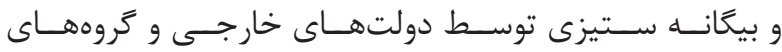

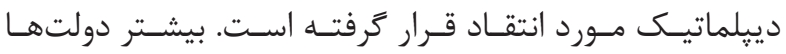

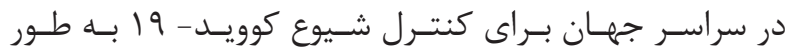

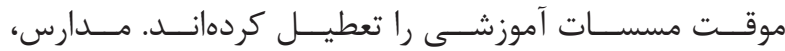

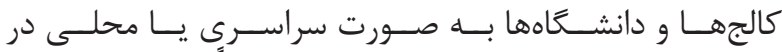

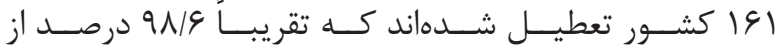

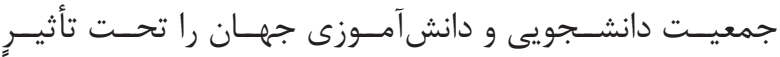

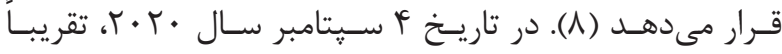

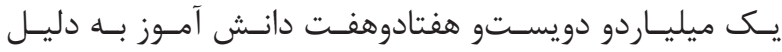

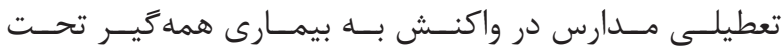




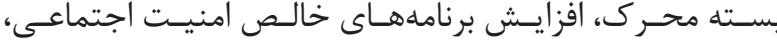

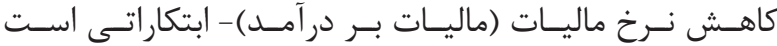

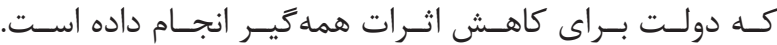

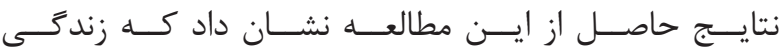

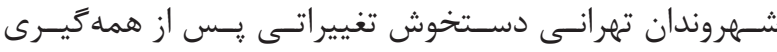

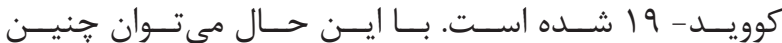

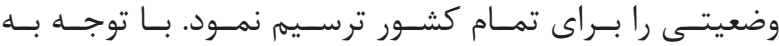

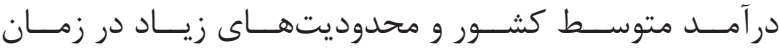

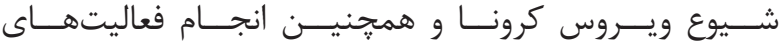

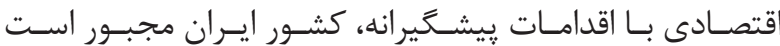

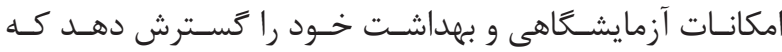

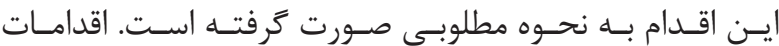

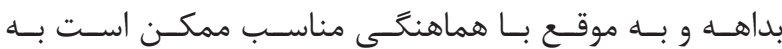

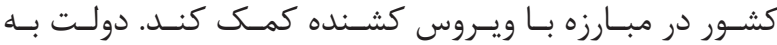

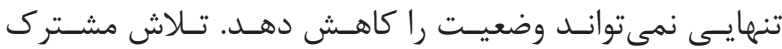

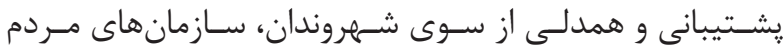

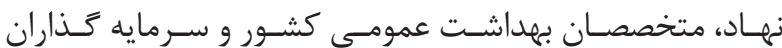

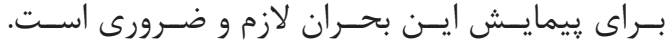

1. Kassegn A, Endris E. Review on socio-economic impacts of 'Triple Threats' of COVID-19, desert locusts, and floods in East Africa: Evidence from Ethiopia. Cogent Social Sciences. 2021; 7(1): 1885122.

2. Sun C, Zhai Z. The efficacy of social distance and ventilation effectiveness in preventing COVID-19 transmission. Sustainable cities and society. 2020;62:102390.

3. Ashcroft P, Lehtinen S, Angst DC, Low N, Bonhoeffer S. Quantifying the impact of quarantine duration on COVID-19 transmission. Elife. 2021; 10: e63704.

4. Cucinotta D, Vanelli M. WHO declares COVID-19 a pandemic. Acta Bio Medica: Atenei Parmensis. 2020; 91(1): 157.

5. Di Fusco M, Shea KM, Lin J, Nguyen JL, Angulo FJ, Benigno M, et al. Health outcomes and economic burden of hospitalized COVID-19 patients in the United States. Journal of Medical Economics. 2021; 24(1): 308-17.

6. Jin H, Wang H, Li X, Zheng W, Ye S, Zhang S, et al. Economic burden of COVID-19, China, JanuaryMarch, 2020: a cost-of-illness study. Bulletin of the World Health Organization. 2021; 99(2): 112.

7. Darab MG, Keshavarz K, Sadeghi E, Shahmohamadi

J, Kavosi Z. The economic burden of coronavirus

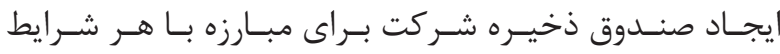

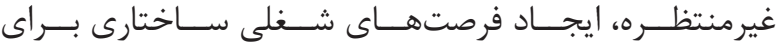

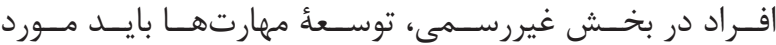

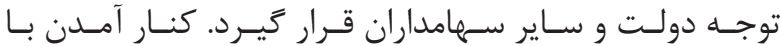

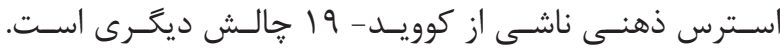

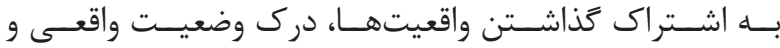

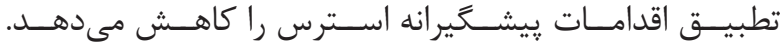

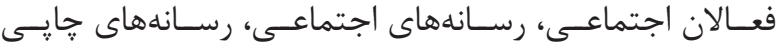

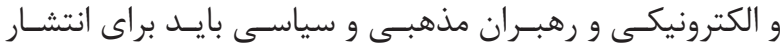

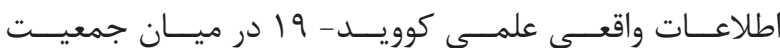

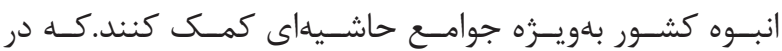

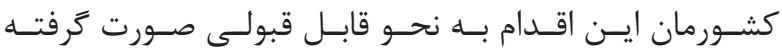

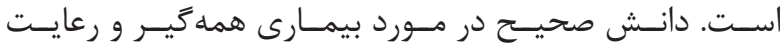

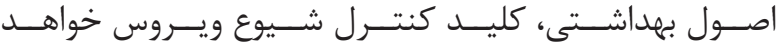

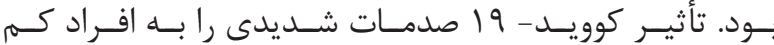

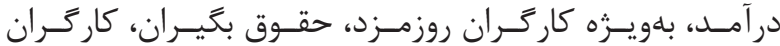

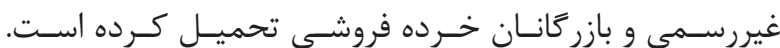

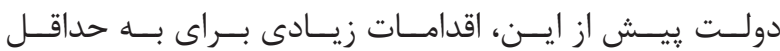

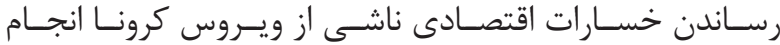

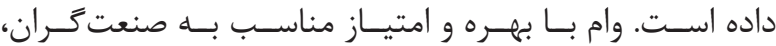

منابع disease 2019 (COVID-19): evidence from Iran. BMC Health Services Research. 2021; 21(1): 1-7.

8. Van Lancker W, Parolin Z. COVID-19, school closures, and child poverty: a social crisis in the making. The Lancet Public Health. 2020; 5(5): e243-e4.

9. Patel J, Nielsen F, Badiani A, Assi S, Unadkat V, Patel B, et al. Poverty, inequality and COVID-19: the forgotten vulnerable. Public health. 2020; 183: 110 .

10. Zhang Y, Diao X, Chen KZ, Robinson S, Fan S. Impact of COVID-19 on China's macroeconomy and agri-food system-an economy-wide multiplier model analysis. China Agricultural Economic Review. 2020.

11. Devi S. Travel restrictions hampering COVID-19 response. The Lancet. 2020; 395(10233): 1331-2.

12. Weed M. The role of the interface of sport and tourism in the response to the COVID-19 pandemic. Taylor \& Francis; 2020.

13. Cluver L, Lachman JM, Sherr L, Wessels I, Krug E, Rakotomalala S, et al. Parenting in a time of COVID-19. Lancet. 2020; 395(10231).

14. Gerard F, Imbert C, Orkin K. Social protection response to the COVID-19 crisis: options for developing countries. Oxford Review of Economic Policy. 2020; 36(Supplement_1): S281-S96. 